\title{
Best-Fit Probability Distribution Model for Rainfall Frequency Analysis of Three Cities in South Eastern Nigeria
}

\author{
Agbonaye, A.I. ${ }^{1} *$ and Izinyon, O.C. ${ }^{1}$ \\ ${ }^{1}$ Department of Civil Engineering, University of Benin, Benin City, Nigeria \\ Corresponding Author: *augustineagbonaye@uniben.edu
}

\begin{abstract}
Rainfall frequency analysis is the estimation of how often rainfall of specified magnitude will occur. Such analyses are helpful in defining policies relating to water resources management. It serves as the source of data for flood hazard mitigation and the design of hydraulic structures aimed at reducing losses due to floods action. In this study rainfall frequency analysis for three (3) cities in South Eastern Nigeria were carried out using annual maximum series of daily rainfall data for the stations. The objective of the study was to select the probability distribution model from among six commonly used probability distribution models namely: Generalized Extreme value distribution $(G E V)$, Extreme value type I distribution (EVI), Generalized Pareto distribution (GPA), Pearson Type III (PIII), log Normal (LN) and Log Pearson Type III (LP111) distributions. These distributions were applied to annual maximum series of daily precipitation data at each station using the parameters of the distributions estimated by the method of moments. The best fit probability distribution model at each location was selected based on the results of seven goodness of fit tests entry: root mean square error (RMSE), relative root mean square error (RRMSE), mean absolute deviation index (MADI) and probability plot correlation coefficient (PPCC), Maximum Absolute Error (MAE), Chi square test and D-Index and a scoring and ranking scheme. Our results indicate that the best fit probability distribution model at all study locations is GEV and this was used to forecast rainfall return values for the stations for return periods of between 5years and 500years. The values obtained are useful for planning, design and management of hydraulic structures for flood mitigation and prevention of flood damage at the location.
\end{abstract}

Keywords: Best Fit, Maximum rainfall; Probability distribution; Goodness of fit, Distribution parameters, Return level

\subsection{Introduction}

The design and construction of certain projects such as dams and urban drainage systems, management of water resources and prevention of flood damage require an adequate knowledge of extreme events of high return periods as worst conditions are normally considered in designs (Tao et al, 2002; Olofintoye 2009. In most cases, the return periods of interest sometimes exceed the period of available records and as such cannot be extracted directly from the recorded data. It is necessary to extrapolate design parameters from the data and this cannot be achieved by other methods. That is why in current engineering practice, the estimation of extreme rainfall depths used for design is accomplished based on statistical frequency analysis of maximum precipitation records. Further stimulation for the study resulted from recent presentation by NIMET of evidence of climate variation especially on the trend of maximum rainfall in 2012 (Okoloye et al, 2014).

As the climate is changing, the necessity to accurately estimate extreme events such as the maximum rainfall frequency has become urgent as it will contribute to the design of safer and more efficient hydraulic structures. Probability distribution models utilized for the analysis of hydrological data are numerous but only few of them had been utilized or applied in previous studies conducted by researchers in Nigeria. 
No particular model is considered superior for all practical purposes hence WMO (2008) recommends that available models are screened on the basis of the problem to be solved and the nature of available data. Data for frequency analysis should be independent and identically distributed hence it is needful to screen candidate distributions for best fit to available data at a location.

\subsection{Materials and Methods}

\subsection{Data and Analysis}

This study entails frequency analysis of annual maximum series of daily rainfall depths of selected cities in South Eastern Nigeria. The three (3) cities selected are: Onitsha, Enugu, and Owerri. The daily rainfall data for the selected cities were obtained from the Nigerian Meteorological Agency (NIMET) Oshodi, Lagos for the period between 1965 and 2012 (48years). Annual maximum series is the series formed from the selection of the highest rainfall value for each of the years under consideration for the stations. The annual series data for each station was tested for homogeneity using Rainbow Software and checked for outliers using HEC-SSP Software. Six probability distribution models namely: Gumbel Extreme Value type 1 (EVI), Generalized Extreme Value (GEV), Generalized Pareto (GPA), LogNormal, and Pearson type III and log Pearson type III were fitted to the annual maximum series data at each location. The details of the descriptive statistics of annual maximum rainfall series and their logarithms are shown in Tables 1a and 1b. The parameters of the fitted distributions were estimated by method of moments (MOM). The best fit model at a location was selected based on results of goodness of fit tests and the application of a scoring and ranking scheme. Subsequently. the best fit model at a location was used to predict rainfall return levels for return periods of engineering design significance (between 5 to 500years).

Table 1a: Summary of Descriptive Statistics of Annual Maximum Rainfall (AMR) for the Stations

\begin{tabular}{|c|c|c|c|c|c|}
\hline S/N & STATION LOCATION & $\begin{array}{c}\text { MEAN } \\
(\mathrm{mm})\end{array}$ & $\begin{array}{c}\text { STANDARD } \\
\text { DEVIATION } \\
(\mathrm{mm})\end{array}$ & SKEWNESS & KURTOSIS \\
\hline 1 & ONITSHA & 97.77 & 38.28 & -0.70 & 1.21 \\
\hline 2 & ENUGU & 85.35 & 39.02 & -0.33 & 0.70 \\
\hline 3 & OWERRI & 111.02 & 36.48 & 0.16 & 0.18 \\
\hline
\end{tabular}

Table 1b: summary of statistics of natural logarithm of annual max. Rainfall (AMR)

\begin{tabular}{|c|c|c|c|c|c|}
\hline S/N & STATION LOCATION & MEAN & $\begin{array}{c}\text { STANDARD } \\
\text { DEVIATION }\end{array}$ & SKEWNESS & KURTOSIS \\
\hline 1 & ONITSHA & 4.3896 & 0.8859 & -2.8054 & 7.2735 \\
\hline 2 & ENUGU & 4.1787 & 1.0341 & -2.3384 & 4.4398 \\
\hline 3 & OWERRI & 4.6738 & 0.3743 & -1.1862 & 2.8414 \\
\hline
\end{tabular}

The details of quantile functions and parameter estimates of the probability distributions utilised are as given in Table 2 
Table 2: Quantile function and parameters of probability distribution ( Vivekananda,Koutsoyiannis)

\begin{tabular}{|c|c|c|c|}
\hline $\mathrm{S} / \mathrm{N}$ & Distribution & Quantile function $\left(\mathrm{R}_{\mathrm{T}}\right)$ & Parameter by MOM \\
\hline 1 & EV1 & $\mathrm{R}_{\mathrm{T}}=\xi-\alpha \ln (-\ln \mathrm{F})$ & $\xi=\bar{R}-0.5772157 \alpha \quad \alpha=(\sqrt{6} / \pi) S_{R}$ \\
\hline 2 & GEV & $\begin{array}{l}\mathrm{R}_{\mathrm{T}}=\xi+\frac{\alpha}{k}(-\ln \mathrm{F})^{-\mathrm{k}}-1 \\
\text { Where } \mathrm{F}=1-\frac{1}{T}\end{array}$ & $\begin{array}{ll}\mathrm{K}=\frac{1}{3}-\frac{1}{0.31+0.91 \mathrm{Csx}+\sqrt{(0.91 \mathrm{Csx})^{2}+1.8}} \\
\alpha=\mathrm{C}_{1} \mathrm{~S}_{\mathrm{x}} & \mathrm{C} 1=\frac{|k|}{\sqrt{\Gamma(1-2 k)}-\Gamma^{2}(1-k)} \\
\mathrm{C} 3=\frac{(\Gamma(1-k)-1)}{k} & \xi=\mathrm{R}_{\mathrm{m}}-\mathrm{C}_{3}\end{array}$ \\
\hline 3 & GPA & $\mathrm{R}_{\mathrm{T}}=\xi+\alpha\left(1-(1-\mathrm{F})^{\mathrm{k}}\right) / \mathrm{k}$ & $\begin{array}{l}\bar{R}=\xi+\alpha /(1+\mathrm{k}) ; \mathrm{S}_{\mathrm{R}}=\alpha^{2} /(1+2 \mathrm{k})(1+\mathrm{k})^{2} \\
\mathrm{C}_{\mathrm{s}}=2(1-\mathrm{k})(1+2 \mathrm{k})^{2} /(1+3 \mathrm{k})\end{array}$ \\
\hline 4 & LN-NOR & $\mathrm{R}_{\mathrm{T}}=\mathrm{e}_{\mathrm{f}}^{\alpha+\mathrm{z}_{\mathrm{k}}}$ & $\mathrm{k}=\sqrt{[}\left[\ln \left(1+\{S x / R m\}^{2}, \alpha=\mathrm{k}^{2} / 2\right.\right.$ \\
\hline 5 & P111 & $\begin{array}{l}\mathrm{R}_{\mathrm{T}}=\xi+\mathrm{Z}_{\mathrm{F}} \alpha \\
\text { Where } \mathrm{Z}_{\mathrm{F}} \text { is obtained from } \\
\text { table }\end{array}$ & $\begin{array}{l}\mathrm{k}=4 / \mathrm{c}_{\mathrm{sx}}^{2}, \alpha=\mathrm{S}_{\mathrm{R}} / \sqrt{k}, \quad \xi=\mathrm{R}_{\mathrm{m}}-\mathrm{k} \alpha \text { where } \\
\mathrm{C}_{\mathrm{Sx}} \text { is coefficient of skewness of obtained } \\
\text { data, } \mathrm{S}_{\mathrm{R}} \text { is standard deviation }\end{array}$ \\
\hline 6 & LN-P111 & $\mathrm{R}_{\mathrm{T}}=\mathrm{e}^{\alpha+\mathrm{z}_{\mathrm{f}}^{*} \mathrm{k}}$ & $\mathrm{K}=4 / \mathrm{C}_{\mathrm{sy}}{ }^{2}, \quad \alpha=\mathrm{S}_{\mathrm{y}} / \sqrt{k}, \xi=\mathrm{R}_{\mathrm{Lm}}-\mathrm{k} \alpha$ \\
\hline
\end{tabular}

In Table 2, $\mathrm{F}(\mathrm{R})$ (or F) is the cumulative distribution function (CDF) of R; P is the probability of exceedance $\xi, \alpha$ and $\mathrm{k}$ are the location scale and shape parameters respectively; $\mu($ or $R), \sigma\left(\right.$ or $\left.S_{R}\right)$ and $C_{s}($ or $\psi)$ are the average, standard deviation and coefficient of skewness of the recorded rainfall data; sign $(\mathrm{k})$ is plus or minus 1 depending on the sign of $\mathrm{k} ; \mathrm{R}_{\mathrm{T}}$ is the estimated rainfall by the probability distribution for a return period $(\mathrm{T})$.

\subsection{Goodness of Fit Test Criteria}

The goodness of fit test used to check the adequacy of fit of probability distribution models to the series of recorded rainfall data for the stations are: Root mean square error (RMSE), Relative root mean square error (RRMSE), Mean absolute deviation index (MADI), Maximum absolute error (MAE), Probability plot correlation coefficient (PPCC), Chi - square $\left(\mathrm{x}^{2}\right)$ test.

It is to be noted that in evaluating the performance of a probability distribution model at a location, the lower the value of the Goodness-of -fit test result the better the distribution except for the PPCC criterion in which the nearer the value is to 1 numerically the better the distribution.

\subsubsection{Root Mean Square Error (RMSE)}

The root mean square was used to measure the difference between values predicted by a model and the observed values. These individual differences are called residuals. The RMSE of a model prediction with respect to the estimated variable $\mathrm{x}$ model was obtained using the formula (Tao et al 2002).

$R M S E=\left(\frac{\sum\left(R_{o}-R_{f}\right)^{2}}{(n-m)}\right)^{\frac{1}{2}}$ 
where $R_{o},\left({ }_{i} i=1, . .2, t o, n\right)$ are observed values, while $R_{f}$ are the corresponding values computed from the assumed probability distribution, $\mathrm{n}$ is the number of observations and $\mathrm{m}$ is the number of parameters estimated for the distribution. The smaller the value of RMSE obtained for a distribution, the more fitted it is to the observed data (Sabri and Arif, 2009; Ahmad et al 2011). Hence smaller value of RMSE for candidate distributions indicate that it is more fitted to the observed data.

\subsubsection{Relative Root Mean Square Error (RRMSE)}

Relative root mean square error was computed by dividing the root mean square error by the mean observed data. The relative root mean square error provides a good picture of the overall fit of a distribution. It computes each error in proportion to the size of observation thereby reducing the effect of outliers which are

Commonly found in hydrological data. RRMSE was computed using the formula (Tao et al 2002):

$$
\text { RRMSE }=\left(\frac{\sum\left(\frac{R_{o i}-R_{f i}}{R_{o}}\right)^{2}}{(n-m)}\right)^{\frac{1}{2}}
$$

Where

$\left.R_{o},{ }_{i} i=1, . .2, t o, n\right)$ are observed values while $R_{f i}$ are the corresponding values computed from the assumed probability distribution, $\mathrm{n}$ is the number of observations, $\mathrm{m}$ is the number of parameters estimated for the distribution. The smaller the value of RRMSE obtained for a distribution, the more fitted it is to the observed data (Sabri and Arif, 2009; Ahmad et al 2011). Hence smaller value of RRMSE for candidate distributions indicate that it is more fitted to the observed data.

\subsubsection{Mean Absolute Deviation Index (MADI)}

The mean absolute deviation index is the average distance between each data value and the mean. It was computed using the formula (Sabri and Arif, 2009; Ahmad et al, 2011):

$$
M A D I=\frac{1}{N} \sum_{i=1}^{N}\left|\frac{R_{o}-R_{f}}{R_{o}}\right|
$$

Where $\mathrm{R}_{0}$ are the observed value, $\mathrm{R}_{\mathrm{f}}$ the value forecasted by the distribution and $\mathrm{N}$ the number of data points. The smaller the value of MADI obtained for a distribution, the more fitted it is to the observed data (Sabri and Arif, 2009; Ahmad et al 2011). Hence smaller value of MADI for candidate distributions indicate that it is more fitted to the observed data.

\subsubsection{Maximum Absolute Error (MAE)}

The maximum absolute error gives the largest absolute difference between the observe (Filliben, 1975) and values predicted by the distributions. MAE was computed using the relationship given by the formula:

$$
M A E=\max \left(\left|R_{o}-R_{f}\right|\right)
$$

Where Ro are the observed values, Rf are the values predicted by the probability distribution model. 
The smaller the value of MAE obtained for a distribution, the more fitted it is to the observed data (Filliben, 1975). Hence smaller value of MAE for candidate distributions indicate that it is more fitted to the observed data.

\subsubsection{Probability Plot Correlation Coefficient (PPCC)}

PPCC is a measure of the correlation between the ordered observations and corresponding fitted values determined by a plotting position equation. PPCC was computed using the relation (Filliben, 1975):

$$
P P C C=\frac{\sum\left\{\left(R_{0 i}-R_{m}\right)\left(R_{f_{i}}-\overline{R_{f m}}\right)\right\}}{\left[\sum\left(R_{0 i}-\bar{R}_{m}\right)^{2} \sum\left(R_{f_{i}}-\overline{R_{f m}}\right)^{2}\right]^{1}}
$$

Where $R_{m}, R_{m f}$ represents the mean values of the observed and forecasted values respectively.

A value of PPCC close to 1 suggest that the observed data could have been drawn from the fitted distributed at a location.

\subsubsection{Chi-Square Test}

Chi-square test is a statistical test commonly used to compare observed data with the data we would expect to obtain according to a specific hypothesis. It is computed using the formula (Vivekananandan, 2014).

$$
x^{2}=\sum_{i=1}^{N} \frac{\left(R_{i}-R^{*}\right)^{2}}{R^{*}}
$$

Where $R_{i}, i, N, R^{*}$ are the year recorded data, year, total year and the expected rain recorded respectively. The smaller the value of Chi- square test value obtained for a distribution, the more fitted it is to the observed data.

\subsubsection{Diagnostic Test (D-Index)}

$\mathrm{D}$ - Index for a distribution was computed using the relationship given by (Vivekananandan, $\mathrm{N}$. 2014):

$$
D-\text { Index }=\left(\frac{1}{R} \sum_{i=1}^{6}\left|R_{i o}-R_{f}\right|\right)
$$

where $R$ is the average (or mean) of recorded Annual maximum Density (AMD), $R_{i_{o}}$, (i=1 to 6) are first six highest sample values in the series and $R_{f}$ is estimated value by probability distribution function (PDF). The distribution having the least $\mathrm{D}$ - index is identified as better suited distribution in Comparison with the other distribution for estimation of maximum rainfall values (Vivekananda, 2014). 


\subsubsection{Scoring and Ranking Scheme}

Based on the results of the goodness of fit tests, a scoring scheme in which the best performing distribution with respect to a test criterion was assigned a score of six (6), the next test was assigned five and the worst test assigned one. The distribution with the highest total score at a location based on the Goodness of fit criteria was adjudged the best distribution model at the station and was selected as the best distribution at the station.

\subsubsection{Forecasting of Rainfall Return Levels at the Station}

The rainfall return levels at a station were computed by substituting the appropriate return period in to the appropriate Quantile function in Table 2 for the applicable best distribution.

\subsection{Results and Discussions}

The procedure outlined in section 2 was followed in the analysis. The results of the various analyses culminating in the selection of the best fit probability distribution model for each station and the rainfall return levels for selected return periods of between 5years and 500 years.

The result of the goodness of fit test results for the distributions at the stations are shown in Table 3 .

Table 3: Goodness-of-Fit Test Results for the Distributions at the Locations

\begin{tabular}{|c|c|c|c|c|c|c|c|}
\hline \multirow{2}{*}{ STATION } & \multirow{2}{*}{$\begin{array}{l}\text { GOF Test } \\
\text { criteria }\end{array}$} & \multicolumn{6}{|c|}{ GOF Test values } \\
\hline & & EV1 & GEV & GPA & LN & P111 & LP111 \\
\hline \multirow{7}{*}{ ENUGU } & RMSE & 13.49 & 10.19 & 33.96 & 21.48 & 11.8 & 14.76 \\
\hline & RRMSE & 2.67 & 1.46 & 7.16 & 2.41 & 1.57 & 1.81 \\
\hline & MADI & 0.78 & 0.357 & 2.23 & 0.75 & 0.38 & 0.55 \\
\hline & MAE & 35.9 & 18.5 & 76.6 & 74.1 & 28.43 & 47.62 \\
\hline & PPCC & 0.9687 & 0.9661 & 0.9893 & 0.9393 & 0.9552 & 0.9945 \\
\hline & CHI- SQ & 12.36 & 37.68 & 619.8 & 757 & 70.95 & 155.6 \\
\hline & D-Index & 0.7986 & 0.827 & 3.41 & 2.855 & 1.074 & 1.598 \\
\hline \multirow{7}{*}{ ONITSHA } & RMSE & 15.46 & 10.65 & 35.25 & 17.44 & 11.04 & 17.27 \\
\hline & RRMSE & 2.49 & 1.38 & 5.86 & 3.55 & 1.48 & 4.49 \\
\hline & MADI & 0.63 & 0.33 & 1.69 & 0.97 & 0.15 & 0.96 \\
\hline & MAE & 45.79 & 33.18 & 91.47 & 62,02 & 32.01 & 58.57 \\
\hline & PPCC & 0.818 & 0.960 & 0.948 & 0.8894 & 0.898 & 0.899 \\
\hline & CHI- SQ & 1077 & 79.39 & 437 & 168 & 53.5 & 166 \\
\hline & D-Index & 0.674 & 0.448 & 2.08 & 0.475 & 0.607 & 0.508 \\
\hline \multirow{7}{*}{ OWERRI } & RMSE & 7.67 & 5.48 & 31.23 & 6.66 & 7.29 & 6.94 \\
\hline & RRMSE & 0.158 & 0.11 & 0.531 & 0.165 & 0.104 & 0.142 \\
\hline & MADI & 0.0208 & 0.0132 & 0.1464 & 0.0335 & 0,00003 & 0.0311 \\
\hline & MAE & 25.8 & 18.7 & 82.2 & 27.0 & 28.3 & 22.7 \\
\hline & PPCC & 0.975 & 0.99 & 0.97 & 0.986 & 0.9868 & 0.9877 \\
\hline & CHI- SQ & 34.99 & 12.40 & 316.5 & 21.80 & 18.65 & 20.43 \\
\hline & D-Index & 0.465 & 0.302 & 2.210 & 0.193 & 0.511 & 0.327 \\
\hline
\end{tabular}

\subsection{Assessment of Probability Distribution Models by Scoring Goodness of Fit Tests Values}

The assessment of the probability distribution models was based on the total score obtained from all the test. The test scores ranging from one to six (1-6) is awarded to each distribution model based on the criteria that the distribution model with the highest score is chosen as the best distribution model for the data of a particular city. The distribution best supported by a test is awarded a score of six (6), the next best is award a score of five (5) and so on in descending order. Using the scoring scheme outlined, Table 4 was computed. The overall ranking results are also presented in Table 4. 
Table 4 Scoring and Ranking Scheme for Distribution at Onitsha

\begin{tabular}{|c|c|c|c|c|c|c|c|}
\hline \multirow[b]{2}{*}{ Station/Region } & \multirow[t]{2}{*}{ Test Criteria } & \multicolumn{5}{|c|}{ Distribution Score } & \multirow[b]{2}{*}{ LP111 } \\
\hline & & EV1 & GEV & $\begin{array}{l}\text { GP } \\
\text { A }\end{array}$ & $\mathrm{LN}$ & $\begin{array}{c}\text { P11 } \\
1\end{array}$ & \\
\hline \multirow{9}{*}{ ONITSHA } & RMSE & 4 & 6 & 1 & 2 & 5 & 3 \\
\hline & RRMSE & 4 & 6 & 1 & 2 & 5 & 3 \\
\hline & MADI & 4 & 5 & 1 & 2 & 6 & 3 \\
\hline & MAE & 4 & 6 & 5 & 1 & 2 & 3 \\
\hline & PPCC & 4 & 6 & 5 & 1 & 2 & 3 \\
\hline & CHI- SQUQRE & 1 & 5 & 2 & 3 & 6 & 4 \\
\hline & D-Index & 2 & 6 & 1 & 5 & 3 & 4 \\
\hline & Total score & 23 & 40 & 16 & 16 & 29 & 23 \\
\hline & Rank & $3^{\text {rd }}$ & $1^{\text {st }}$ & $4^{\text {th }}$ & $4^{\text {th }}$ & $2^{\text {nd }}$ & $3^{\text {rd }}$ \\
\hline \multirow{9}{*}{ ENUGU } & RMSE & 4 & 6 & 1 & 2 & 5 & 3 \\
\hline & RRMSE & 2 & 6 & 1 & 3 & 5 & 4 \\
\hline & MADI & 2 & 6 & 1 & 3 & 5 & 4 \\
\hline & MAE & 4 & 6 & 1 & 2 & 5 & 3 \\
\hline & PPCC & 4 & 3 & 5 & 1 & 2 & 6 \\
\hline & CHI- SQUQRE & 1 & 6 & 2 & 3 & 5 & 4 \\
\hline & D-Index & 6 & 5 & 1 & 2 & 4 & 3 \\
\hline & Total score & 23 & 39 & 12 & 16 & 31 & 27 \\
\hline & Rank & $4^{\text {th }}$ & $1^{\text {st }}$ & $6^{\text {th }}$ & $5^{\text {th }}$ & $2^{\text {nd }}$ & $3^{\text {rd }}$ \\
\hline \multirow{9}{*}{ OWERRI } & RMSE & 2 & 6 & 1 & 5 & 3 & 4 \\
\hline & RRMSE & 3 & 5 & 1 & 2 & 6 & 4 \\
\hline & MADI & 4 & 4 & 1 & 2 & 6 & 3 \\
\hline & MAE & 4 & 6 & 1 & 3 & 2 & 5 \\
\hline & PPCC & 2 & 6 & 1 & 3 & 4 & 5 \\
\hline & CHI- SQUQRE & 2 & 6 & 1 & 3 & 5 & 4 \\
\hline & D-Index & 3 & 5 & 1 & 6 & 2 & 4 \\
\hline & Total score & 20 & 39 & 7 & 24 & 28 & 29 \\
\hline & Rank & $5^{\text {th }}$ & $1^{\mathrm{st}}$ & $6^{\text {th }}$ & $4^{\text {th }}$ & $3^{\text {rd }}$ & $2^{\text {nd }}$ \\
\hline
\end{tabular}

Ranking the total scores, a summary of the performance of the six probability models was obtained as shown on Table 5. The table detailed the Best-fit-model and the second best fit model for each location with their scores.

Table 5: Goodness of fit test and the selected model for the peak rainfall

\begin{tabular}{|c|c|c|c|c|c|}
\hline S/N & LOCATION & BEST FIT MODEL & $\begin{array}{c}\text { TOTAL } \\
\text { MAX } \\
\text { SCORE }\end{array}$ & $\begin{array}{c}\text { SECOND } \\
\text { BEST FIT } \\
\text { MODEL }\end{array}$ & $\begin{array}{c}\text { TOTAL MAX } \\
\text { SCORE }\end{array}$ \\
\hline 1 & ONITSHA & Generalized Extreme Value & 40 & Pearson III & 29 \\
\hline 2 & ENUGU & Generalized Extreme Value & 39 & Pearson III & 31 \\
\hline 3 & OWERRI & Generalized Extreme Value & 39 & Log-Pearson III & 29 \\
\hline
\end{tabular}

The best fit probability distribution shown in the Table 5 were used to compute the Quantile values in Table 6. The results of the various analyses culminating in the selection of the best fit probability distribution model for each station and the rainfall return levels $(\mathrm{mm})$ for selected return periods of between 5years and 500 years is as presented in Table 6 .

Table 6: Predicted rainfall return levels (mm) at the study locations

\begin{tabular}{|c|c|c|c|c|c|c|c|c|}
\hline \multirow{2}{*}{ Location } & \multirow{2}{*}{$\begin{array}{c}\text { Best fit } \\
\text { distribution }\end{array}$} & 5 & 10 & 25 & 50 & 100 & 200 & 500 \\
\cline { 5 - 10 } & GEV & 132 & 145 & 151 & 153.94 & 160.42 & 162.52 & 164.35 \\
\hline Onitsha & GEV & 112 & 135 & 148.57 & 155.95 & 161.68 & 165.88 & 169.95 \\
\hline Enugu & GEV & 144.14 & 161.63 & 178.89 & 191.33 & 200.98 & 209.23 & 218.35 \\
\hline Owerri & &
\end{tabular}




\subsection{Rainfall Frequency Curves (RFCS)}

The AMR estimates obtained for the probability distribution models in Table 6 were used to develop the RFCs and presented in Figures 1 to 3.

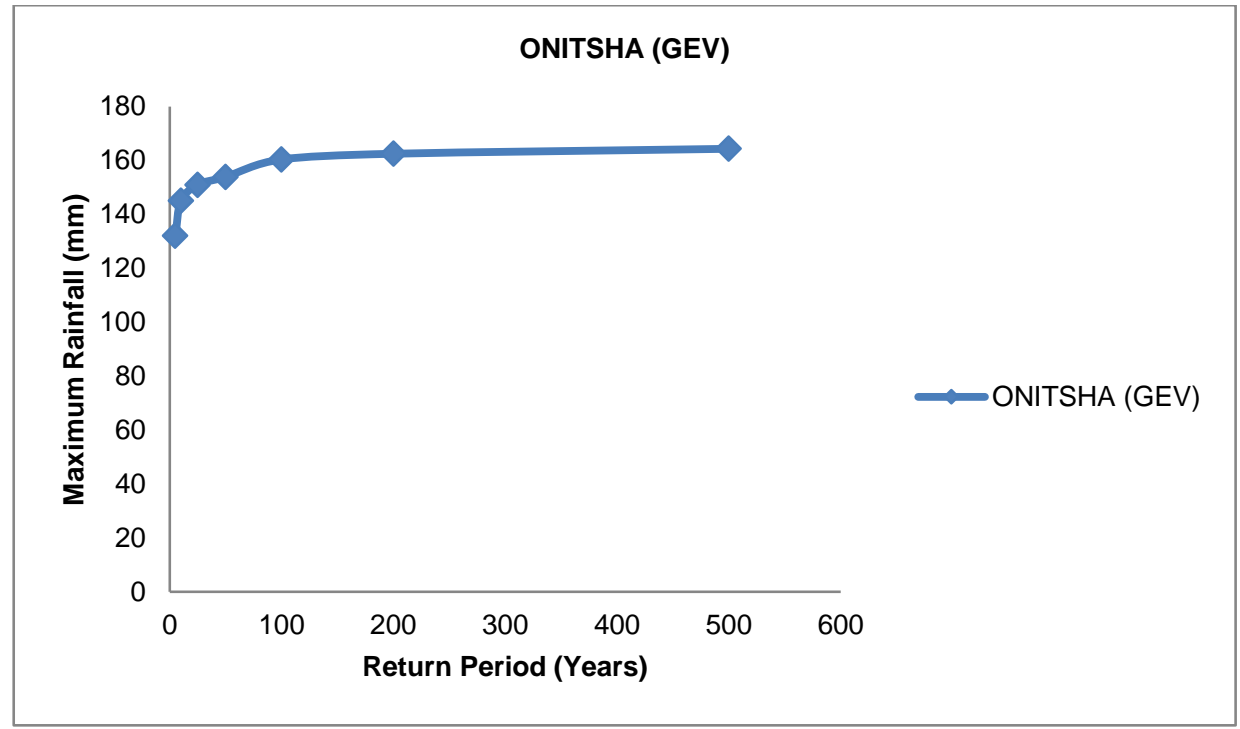

Figure 1: Rainfall Frequency Curve for Onitsha

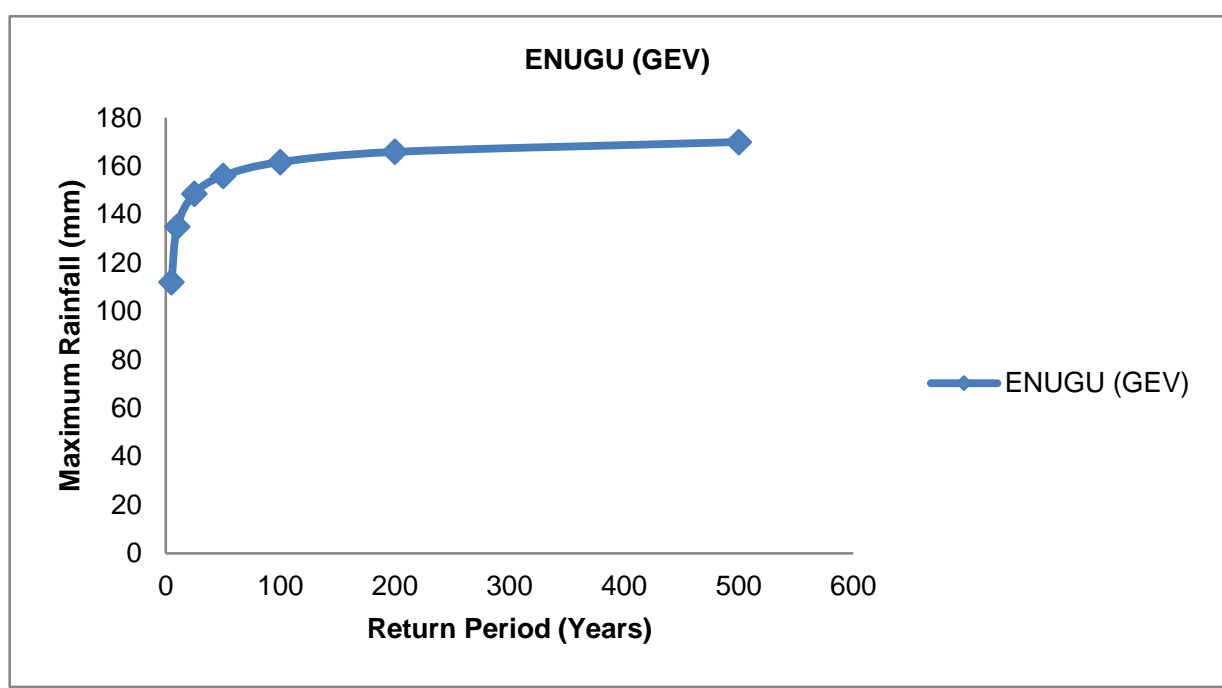

Figure 2: Rainfall Frequency Curve for Enugu

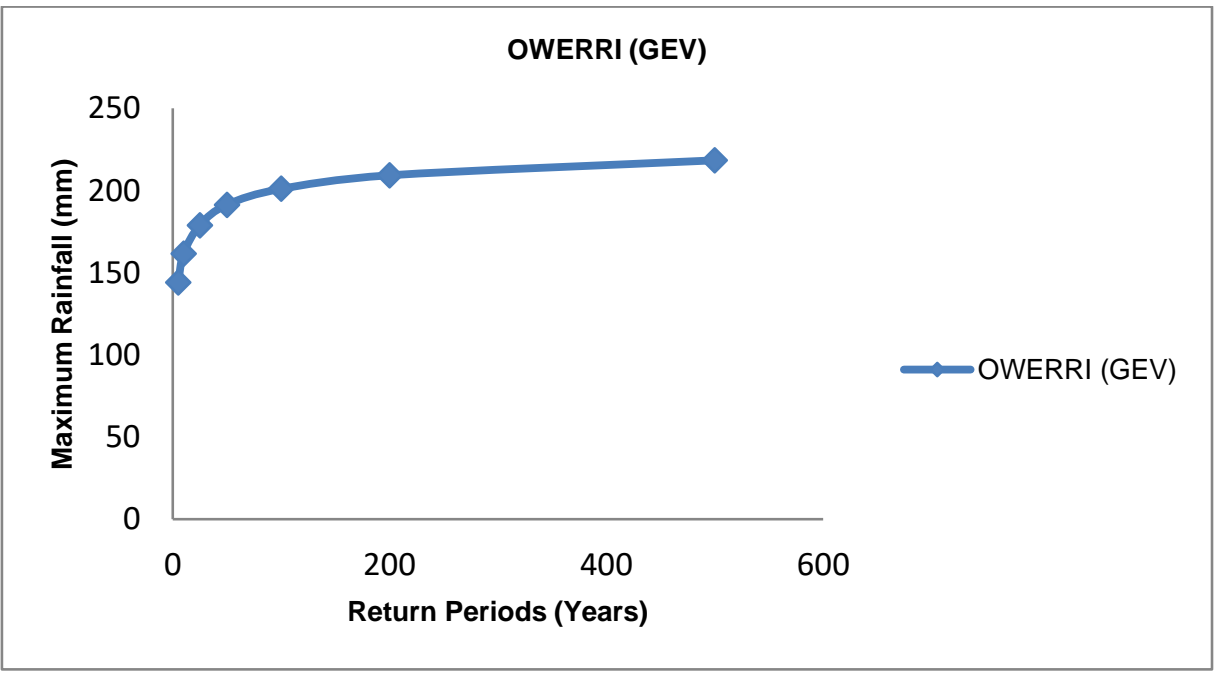

Figure 3: Rainfall Frequency Curve for Owerri 


\subsection{Conclusions}

In this study the best-fit probability distribution model applicable to each location were selected for three cities in South Eastern Nigeria from six probability distributions and used to predict rainfall return levels of engineering importance for the location. Based on the results the following conclusions are made:

1. GEV model is best-fit probability model at all the locations. The Quantile estimates or forecasted rainfall values for different return periods as shown in Table 6 are considered adequate design parameters for planning and design of hydraulic structures for flood mitigation and flood precautions in the various locations.

2. Rainfall frequency curves provided for each location and drawn with the forecasted rainfall values that were derived from the best fit probability distribution models, provide guides in hydrological designs.

3. In this era of frequent collapses of bridges, houses, dams, drainages as a result of improper design, it is necessary for engineers to take all necessary statistical inputs into design process for effective works. This study has provided useful Engineering Design Parameters for Planning and improved Hydrological design needed for Efficient Hydraulic design of Structures needed for flood control, mitigation and flood precaution in the various location. Utilization of these parameters by engineers will greatly reduce or advert design failures.

\section{References}

Filliben, J.J. (1975) The Probability Plot Correlation Coefficient Test For Normality. Technometrics Vol.17 No 1, pp.111-117

Koutsoyiannis, D. (1997): Statistical Hydrology Edition 4, 312 pages, National Tech. University of Athens.

Okoloye, C.U. (2014): Rainfall variability and the recent climate extremes in Nigeria, NIMET, National Weather Forecast and climate research centre, Journal of Meteorology and Climate Science.

Olofintoye, O.O., Sule, B.F. and Salami, A.W. (2009): Best - fit probability distribution model for peak daily of selected cities in Nigeria. New York science journal, 2(3) ISSN $1554-0200$.

Tao, D.Q., Nguyen, V.T. and Bourque, A. (2002). On selection of probability distribution for representing extreme Precipitations in southern Quebee. Annual conference of the Canadian Society for Civil Engineering. Pp $1-8$

Vivekananandan, N. (2014): Comparison of probability distributions for frequency analysis of annual 44maximum rainfall, international journal of research and innovative technology vol. 1 issue 3 pp-54

World Meteorological Organization (WMO) (2009); Guide to Hydrological Practices: Voll.11; Management of Water Resources and Application of Hydrological Practices, No.168 six Ed.Ch, pp11.2,World Meteorological Organization, Geneva, Switzerland. 